\title{
ESTUDO DA CIRCULAÇÃO DOS VENTOS NA BAÍA DE GUANABARA/RJ, ENTRE 2003 E 2013
}

\author{
OLIVEIRA-JÚNIOR, José Francisco - joliveirajunior@gmail.com \\ Intituto de Ciências Atmosféricas/ICAT - Universidade Federal de Alagoas / \\ UFAL
}

\author{
TERASSI, Paulo Miguel de Bodas - pmbterassi@usp.br \\ Programa de Pós-Graduação em Geografia Física, Universidade de São \\ Paulo / USP \\ GOIS, Givanildo - givanildogois@gmail.com \\ Escola de Engenharia Industrial Metalúrgica de Volta Redonda, Centro \\ Tecnológico, Universidade Federal Fluminense / UFF
}

\begin{abstract}
RESUMO: A cidade do Rio de Janeiro e a sua região metropolitana apresentam atributos fisiográficos como a existência de maciços, lagoas, floresta urbana, manguezais e a Baía de Guanabara, que interagem com a circulação local e de mesoescala dos ventos. 0 objetivo deste estudo é avaliar o padrão de circulação de ventos na Baía de Guanabara no período de 2003 a 2013. Foram utilizados os dados do código METAR (Meteorological Aerodrome Report) das Estações Meteorológicas de Superfície dos Aeroportos do Galeão (SBGL) e Santos Dumont (SBGRJ). Na análise dos ventos foi criado um pré-processador em linguagem FORTRAN para extração da velocidade e direção do vento do código METAR dos aeroportos e, depois representados pela rosa dos ventos e histogramas pelo software WRPLOT. A série temporal de vento foi submetida ao teste Run na escala anual. O teste Run mostrou que ambas as estações SBGL e SBRJ são livres de correlação serial ou persistência temporal, as exceções foram os anos de 2005, 2006 e 2009. A direção dos ventos para a escala anual mostrou que a Estação SBGL apresenta ventos predominantes de sudeste e leste, ao passo que a Estação SBRJ, com maior influência da brisa marítima dada a sua maior proximidade com o Oceano Atlântico, registrou o domínio de ventos de sul (>32\%). O padrão cíclico diário de direção dos ventos indicou que na Estação SBRJ a influência da brisa marítima é mais notável em comparação à Estação SBGL.
\end{abstract}

Palavras- chaves: Brisa marítima, Direção e Velocidade do vento, Padrão cíclico diário, Brisa de baía.

\section{STUDY OF THE WIND CIRCULATION IN GUANABARA BAY/RJ BETWEEN 2003 TO 2013}

ABSTRACT: The Rio de Janeiro city and it metropolitan area presents physiographic attributes such as the existence of massifs, lagoons, urban forest, mangroves and Guanabara Bay, which interact with local and mesoscale wind circulation. This paper aims is to evaluate the wind pattern circulation in Guanabara Bay from 2003 to 2013. Were used the data from METAR (Meteorological Aerodrome Report) code of the Surface Meteorological Stations of the Galeão (SBGL) and Santos Dumont (SBGRJ) Airports. In the winds analysis the language processor FORTRAN was created to extract the speed and wind direction of the Airports METAR code and represented in winds rose and histograms by WRPLOT software. The temporal wind series was submitted to the Run test on the annual scale. The Run test showed that both the SBGL and SBRJ stations are free of serial correlation or time persistence, being the exceptions in 2005, 2006 and 2009 years. The wind direction for the annual scale showed that the SBGL Station presents prevailing southeast and east winds, while the SBRJ Station, with greater sea breeze influence due to its greater proximity to the Atlantic Ocean, registrered the dominance of south winds (>32\%). The daily cyclical pattern of wind direction indicated that in the SBRJ Station the influence of the sea breeze is more remarkable in comparision to the SBGL Station. 
Keywords: Sea breeze, Direction and Speed wind, Daily cyclical pattern, Bay breeze

\section{INTRODUÇÃO}

Os estudos que foram realizados com intuito de avaliar a atuação da circulação das brisas nas areas de baías no Brasil são inexistentes, visto que elas podem ser consideradas como brisas lacustres. Ressalta-se que na circulação de brisa de baía ocorre a interação da circulação local e de mesoescala, não sendo descartada a interação com escala sinótica, semelhante ao observado para brisas lacustres continentais (STIVARI et al., 2003). Desta forma, destaca-se que a maioria dos estudos se restringe a circulação das brisas marítimo-terrestres e que têm sido estudadas extensivamente em diversas regiões do mundo, sendo que em um primeiro momento por meio de observações de superfície e altitude (DEFANT, 1951) e, em seguida, por meio dos primeiros modelos lineares (ARRITT, 1989) e, mais recentemente, por meio dos modelos numéricos de mesoescala (BONNARDOT et al., 2005).

A brisa marítima é um fenômeno de mesoescala comum em muitas áreas costeiras ao redor do mundo e tem sido observada e documentada há várias décadas (NEUMANN, 1973). Durante a metade do século passado, várias pesquisas foram dedicadas à observação, aos estudos teóricos e de modelagem numérica na avaliação da circulação da brisa marítima (PIELKE, 1974; ATKINSON, 1981; ABBS e PHYSICK, 1992; SIMPSON, 1994).

Prahba et al. (2002) descreve a brisa marítima como uma circulação que se desenvolve a partir do aquecimento diferencial entre o continente e o oceano. Estes autores descrevem que a intensidade, a extensão vertical e horizontal da brisa marítima depende do escoamento sinótico, da diferença da temperatura de superfície entre o continente e oceano e da estrutura da Camada Limite Atmosférica (CLA). Diversos pesquisadores notaram que a direção e a intensidade do escoamento sinótico influenciam a estrutura da brisa marítima (ESTOQUE, 1962; PIELKE, 1974; ZERI et al., 2016). Outros fatores também influenciam a brisa marítima, tais como: o gradiente horizontal de pressão, 0 tipo de uso e ocupação do solo, a topografia costeira, a cobertura de nuvem, a Temperatura da Superfície do Mar (TSM) e a variação latitudinal do parâmetro de Coriolis (YAMARTINO, 1984; OLIVEIRA JÚNIOR et al., 2013).

A Região Metropolitana do Rio de Janeiro (RMRJ) possui topografia acidentada, presença de corpos d'água e regimes de ventos diferenciados. Este recorte espacial é influenciado por diversos aspectos meteorológicos que variam desde a escala sinótica a local, que por sua vez interferem no regime de escoamento da região, particularmente a circulação das brisas marítimas e terrestres (PIMENTEL et al., 2014).

De acordo com Pimentel et al. (2014), o regime de vento na Baía de Guanabara, que circunda a RMRJ, é dominado pelo escoamento de grande escala com maior frequência dos ventos de nordeste (NE) associado ao Anticiclone Subtropical do Atlântico Sul (ASAS), domínio este que é perturbado quando da passagem de Sistemas Frontais (SF) e alterado localmente pelo efeito da circulação das brisas marítima/terrestre (OLIVEIRA JÚNIOR et al., 2013; BRITO et al., 2016). Sobretudo, as condições da brisa marítima na RMRJ influenciam fortemente as concentrações dos poluentes, com o escoamento carregando esses poluentes para locais distantes das fontes (LYRA et al., 2011; 
ZERI et al., 2011), na formação e intensificação da Ilha de Calor Urbana (ICU), conforme identificada na RMRJ por Moraes et al. (2005) e Moraes (2008) e na formação de chuvas intensas (DERECZYNSKI et al., 2009).

Martins et al. (2004) avaliaram o regime de vento na RMRJ por meio de informações horárias do Aeroporto Internacional Rio de Janeiro (Galeão). Os resultados mostraram a ocorrência intensificada de brisas marítimas na área, onde se situa o aeroporto nos meses de verão. Contudo, a penetração da brisa no continente não pode ser evidenciada, em função da falta de informações nas demais regiões a sotavento.

Tayt-Sohn et al. (2010) avaliaram a influência da circulação da brisa marítima na ICU por meio de simulações obtidas do modelo MM5 (Model Mesoscale 5) e concluíram que dependendo da intensidade e penetração da brisa marítima pode ser um mecanismo eficiente na formação e desintensificação da ICU na RMRJ. Entretanto, o estudo se limita na avaliação conjugada do campo horizontal do vento e da temperatura, e não avalia a extensão vertical da circulação da brisa marítima na RMRJ.

Considerando o exposto, afirma-se que a RMRJ apresenta diversas características fisiográficas como, por exemplo, a existência de maciços, lagoas, e a Baía de Guanabara que interagem com a circulação local e de mesoescala. Com esta perspectiva, o objetivo desse estudo é avaliar o padrão de circulação de ventos na Baía de Guanabara no período de 2003 a 2013 a partir da utilização dos dados de duas Estações Meteorológicas de Superfície (EMS) situadas nas proximidades da referida Baía.

\section{MATERIAIS E MÉTODOS}

A área de estudo corresponde à Baía de Guanabara, estado do Rio de Janeiro, que está localizada aproximadamente entre as latitudes $22^{\circ} 43^{\prime}$ e

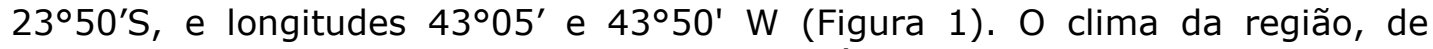
acordo com classificação de Köppen (1936), é "Aw", caracterizada por verões quentes e chuvosos e invernos secos e amenos (ÁLVARES et al., 2013). A temperatura média anual é de $23,9^{\circ} \mathrm{C}$ e a máxima e mínima são $27,3^{\circ} \mathrm{C}$ no verão e $21,1^{\circ} \mathrm{C}$ no inverno, respectivamente, com chuva $1.258 \mathrm{~mm}$.ano-1 e número médio de 124 dias com chuvas (ZERI et al., 2011).

A RMRJ possui características peculiares como a topografia acentuada, a Baía de Guanabara e a proximidade com Oceano Atlântico, características geográficas capazes de gerar efeitos locais que perturbam o regime de escoamento na região. Na topografia da região destacam-se três maciços: Tijuca, Pedra Branca e Gericinó. Os Maciços da Tijuca e da Pedra Branca estendem-se do continente até o Oceano Atlântico, no sentido sudeste (Tijuca) e sudoeste (Pedra Branca) - (OLIVEIRA-JúNIOR et al., 2015). Outra característica marcante da RMRJ é a diversificação do uso e cobertura do solo, com a predominância de áreas urbanas (MORAES, 2008). Possui também uma alta densidade populacional e elevada industrialização, responsáveis pela grande concentração de fontes poluidoras (ZERI et al., 2011; SANTOS et al., 2016) e pela formação da ICU (MORAES et al., 2005). 


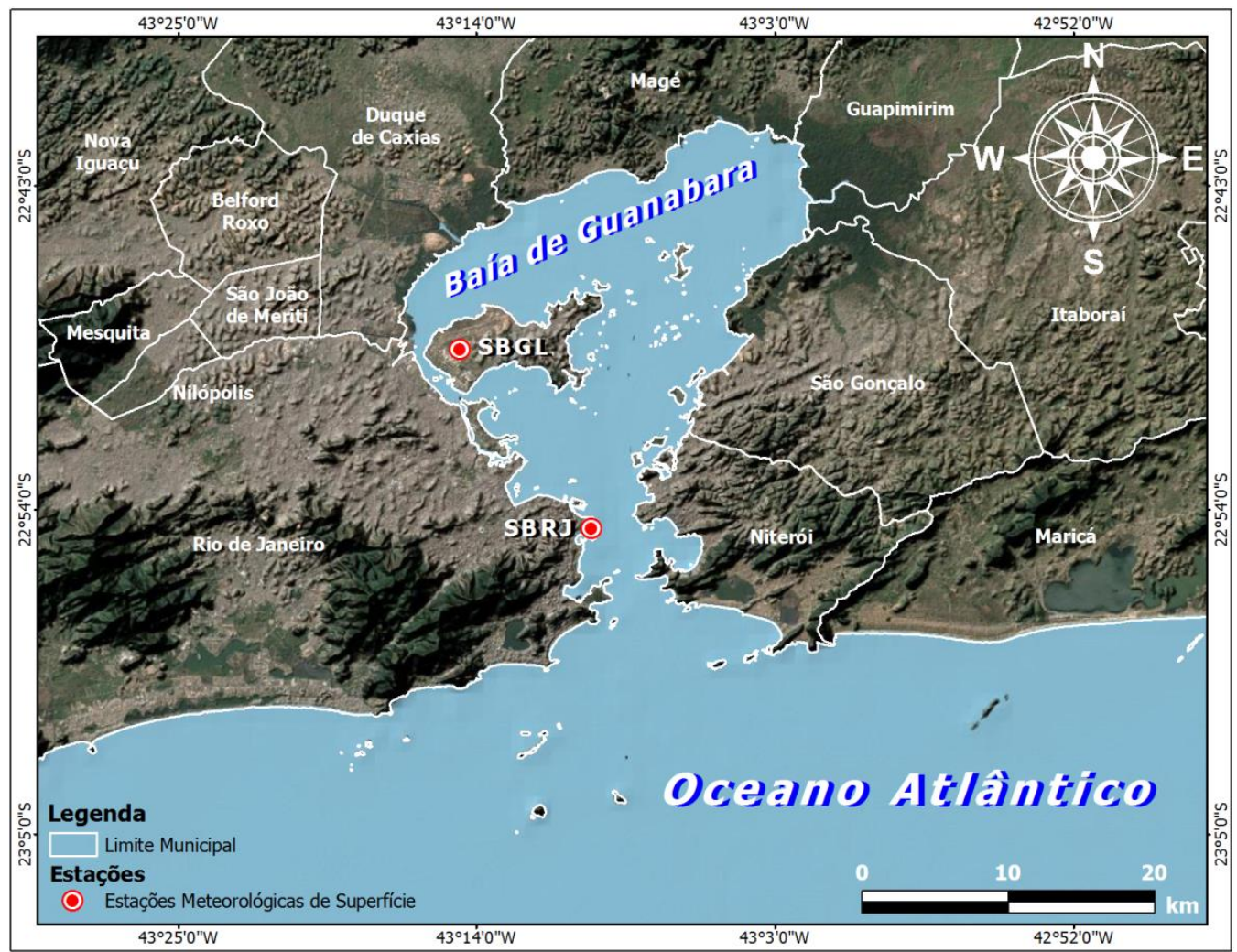

Figura 1 - Localização da Baía de Guanabara e das Estações Meteorológicas de Superfície (SBGL e SBRJ) em estudo.

Realizou-se a análise dos padrões de vento (velocidade e direção do vento) que atuaram na Baía de Guanabara entre 2003 e 2013. Nela utilizaramse os dados do código METAR (Meteorological Aerodrome Report) das Estações Meteorológicas de Superfície (EMS) dos Aeroportos Internacional Galeão (SBGL) e Nacional Santos Dumont (SBRJ) (Tabela 1). Na Baía de Guanabara as estações supracitadas são as únicas com séries temporais de vento de forma consistente e com poucas falhas, segundo a tabela 2 . Os dados de velocidade e direção do vento foram disponibilizados pela Rede de Meteorologia do Comando da Aeronáutica (REDEMET, 2017).

Tabela 1 - Coordenadas geográficas, identificação e fonte dos dados de velocidade e direção do vento das estações meteorológicas de superfície do SBGL e SBRJ.

\begin{tabular}{cccccc}
\hline Estações & Identificação & LAT $\left(^{\circ}\right)$ & LON $\left(^{\circ}\right)$ & $\begin{array}{l}\text { ALT } \\
(\mathbf{m})\end{array}$ & FONTE \\
\hline SBGL & 83746 & $22^{\circ} 48^{\prime \prime} \mathrm{S}$ & $43^{\circ} 15^{\prime \prime} \mathrm{W}$ & $9 \mathrm{~m}$ & METAR \\
SBRJ & 83755 & $22^{\circ} 54^{\prime \prime} \mathrm{S}$ & $43^{\circ} 10^{\prime \prime} \mathrm{W}$ & $3 \mathrm{~m}$ & METAR \\
\hline
\end{tabular}

Fonte: REDEMET

Para a sistematização dos dados criou-se um pré-processador em linguagem FORTRAN para a extração da direção $\left(^{\circ}\right)$ e velocidade do vento (m.s$\left.{ }^{1}\right)$ nas presentes estações de superfície. Estas informações foram utilizadas para a elaboração das rosas de vento e histogramas por meio do programa WRPLOT (LAKES ENVIRONMENTAL SOFTWARE, 2017). As rosas dos ventos e histogramas 
de classes de intensidade dos ventos foram divididas nas seguintes escalas: ciclos diários (0 até $23 \mathrm{~h}$ ), sazonais e anuais. Após os dados serem organizados, foi feita análise estatística exploratória por meio do boxplot via o software ambiente $R$ versão 3.3.2 ( $R$ DEVELOPMENT CORE TEAM, 2016). Por meio do boxplot identificaram-se possíveis valores extremos (outliers) no regime de vento das estações do SBGL e SBRJ, respectivamente.

Os dados utilizados pelas estações SBRJ e SBGL apresentam poucas diferenças, as exceções foram a quantidade de registros incompletos e a disponibilidades de dados (Tabela 2). Todas as informações foram extraídas no programa WRPLOT.

Tabela 2 - Informações gerais dos dados utilizados das estações meteorológicas de superfície do SBGL e SBRJ.

\begin{tabular}{cccccc}
\hline Estações & $\begin{array}{c}\text { Número } \\
\text { total de } \\
\text { horas de } \\
\text { Observação }\end{array}$ & $\begin{array}{c}\text { Disponibilidade } \\
\text { de } \\
\text { Dados }\end{array}$ & $\begin{array}{c}\text { Registros } \\
\text { Incompletos } \\
\text { /Ausentes }\end{array}$ & $\begin{array}{c}\text { Total de } \\
\text { Registros } \\
\text { Usados }\end{array}$ & $\begin{array}{c}\text { Registros } \\
\text { Calmarias } \\
\text { Calmarian }\end{array}$ \\
\hline SBGL & 96.227 & $96,79 \%$ & 3091 & 93.140 & 7711 \\
SBRJ & 96.274 & $87,79 \%$ & 11751 & 84.523 & 5145 \\
\hline
\end{tabular}

A série temporal de vento utilizada no estudo não sofreu nenhum preenchimento de falhas, visto que a disponibilidade de dados foi superior a $87 \%$ dos dados em ambas as estações de superfície. As falhas existentes são registros horários e estão organizadas nas escalas mensais e anuais, conforme as tabelas 3 e 4 . Devido às eventuais falhas nas estações usadas no estudo, optou-se pela aplicação do teste Run aplicada à série temporal de vento na escala anual para a seleção de anos com correlação serial. Após a identificação destes anos, realizou-se a consulta aos boletins do Climanálise (2017) para associar a atuação dos sistemas atmosféricos com o regime de ventos.

Tabela 3 - Distribuição do número de falhas nos registros horários da estação SBGL entre 2003-2013.

\begin{tabular}{|c|c|c|c|c|c|c|c|c|c|c|c|c|}
\hline 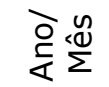 & JAN & FEV & MAR & ABR & MAI & JUN & JUL & AGO & SET & OUT & NOV & DEZ \\
\hline 2003 & 10 & 3 & 0 & 3 & 0 & 4 & 13 & 71 & 1 & 4 & 3 & 11 \\
\hline 2004 & 61 & 70 & 140 & 26 & 69 & 323 & 47 & 314 & 0 & 4 & 770 & 740 \\
\hline 2005 & 6 & 123 & 161 & 0 & 6 & 24 & 0 & 1 & 2 & 0 & 0 & 0 \\
\hline 2006 & 1 & 2 & 4 & 1 & 2 & 1 & 0 & 0 & 0 & 0 & 0 & 0 \\
\hline 2007 & 4 & 1 & 0 & 3 & 25 & 0 & 0 & 0 & 0 & 0 & 1 & 1 \\
\hline 2008 & 2 & 0 & 1 & 0 & 0 & 0 & 0 & 0 & 0 & 0 & 0 & 1 \\
\hline 2009 & 0 & 0 & 0 & 0 & 0 & 0 & 2 & 2 & 1 & 2 & 4 & 1 \\
\hline 2010 & 0 & 0 & 1 & 0 & 0 & 0 & 0 & 0 & 0 & 0 & 1 & 0 \\
\hline 2011 & 0 & 0 & 0 & 1 & 1 & 0 & 0 & 0 & 0 & 2 & 1 & 1 \\
\hline 2012 & 0 & 0 & 0 & 0 & 0 & 1 & 0 & 0 & 0 & 0 & 0 & 0 \\
\hline 2013 & 0 & 0 & 0 & 0 & 0 & 0 & 0 & 0 & 0 & 0 & 0 & 0 \\
\hline
\end{tabular}

Tabela 4 - Distribuição do número de falhas nos registros horários da estação SBRJ entre 2003-2013. 


\begin{tabular}{|c|c|c|c|c|c|c|c|c|c|c|c|c|}
\hline 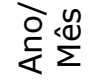 & JAN & FEV & MAR & ABR & MAI & JUN & JUL & AGO & SET & OUT & NOV & DEZ \\
\hline 2003 & 11 & 2 & 1 & 17 & 5 & 8 & 13 & 77 & 0 & 5 & 3 & 12 \\
\hline 2004 & 72 & 70 & 141 & 28 & 97 & 323 & 44 & 314 & 2 & 4 & 720 & 740 \\
\hline 2005 & 6 & 123 & 162 & 0 & 5 & 23 & 0 & 2 & 3 & 0 & 0 & 2 \\
\hline 2006 & 1 & 1 & 3 & 2 & 2 & 3 & 0 & 2 & 1 & 1 & 0 & 0 \\
\hline 2007 & 3 & 1 & 0 & 5 & 25 & 0 & 1 & 1 & 0 & 0 & 0 & 0 \\
\hline 2008 & 3 & 0 & 0 & 0 & 0 & 0 & 0 & 0 & 0 & 0 & 0 & 0 \\
\hline 2009 & 0 & 0 & 0 & 0 & 0 & 0 & 3 & 0 & 1 & 1 & 7 & 183 \\
\hline 2010 & 184 & 168 & 186 & 180 & 186 & 180 & 186 & 186 & 180 & 188 & 180 & 186 \\
\hline 2011 & 185 & 168 & 186 & 180 & 187 & 180 & 186 & 186 & 180 & 186 & 194 & 187 \\
\hline 2012 & 184 & 161 & 186 & 178 & 184 & 180 & 185 & 207 & 180 & 186 & 179 & 186 \\
\hline 2013 & 186 & 168 & 186 & 180 & 155 & 149 & 125 & 155 & 150 & 155 & 150 & 154 \\
\hline
\end{tabular}

O teste de Run é um teste não paramétrico que avalia se uma série temporal se distribui de forma aleatória, sendo bastante usado na literatura (BACK, 2010; TEODORO et al., 2015). O teste se baseia na contagem do número de oscilações dos valores superiores (codificado com 1) e abaixo (codificado com 0) da mediana, numa série de dados naturalmente ordenada.

O número de oscilações é chamado de "run", e deve-se testar se o valor observado está dentro da faixa de distribuição considerada normal. Um valor alto de "run" indica várias oscilações, enquanto os valores baixos indicam um desvio em relação à mediana durante o período de registros. Deste modo, se a sequência contém $N_{1}$ símbolos de um tipo, e $N_{2}$ símbolos de outro tipo $\left(N_{1}\right.$ e $N_{2}$ não são muito pequenos), a distribuição amostral do número de "runs" total pode ser aproximada pela distribuição normal com média descrita pela Eq. 1, e a variância da distribuição com base na Eq. 2:

$$
\begin{aligned}
& E(u)=\frac{2 N_{1} N_{2}}{N_{1} N_{2}}+1 \\
& \operatorname{Var}(u)=\frac{2 N_{1} N_{2}\left(2 N_{1} N_{2}-N_{1} N_{2}\right)}{\left(N_{1} N_{2}\right)^{2}\left(2 N_{1} N_{2}-1\right)}
\end{aligned}
$$

Nestas relações u representa o número de "runs". Desta forma, a hipótese nula ( $\mathrm{HO})$ de que a distribuição dos símbolos ocorre normalmente e que a amostra é aleatória, pode ser testada com base na estatística descrita pela Eq. 3:

$$
Z=\frac{u-E(u)}{\sqrt{\operatorname{Var}(u)}}
$$

O valor calculado pode ser comparado com valores de $z$ para distribuição normal. Para o nível de significância de $5 \%$ de probabilidade, $z$ encontra-se entre o intervalo $-1,96$ a $+1,96$. Caso $z$ calculado seja maior que o valor tabelado, rejeita-se a hipótese de nulidade $\left(\mathrm{H}_{0}\right)$. Para o cálculo do teste Run foi utilizado o pacote "randtests" do software ambiente $R$ versão 3.3.2 (R DEVELOPMENT CORE TEAM, 2016). 


\section{RESULTADOS E DISCUSSÕES}

\subsection{AVALIAÇÃO ANUAL DA DIREÇÃO E VELOCIDADE DOS VENTOS}

As direções predominantes do vento identificadas para a Estação SBGL, localizado na Ilha do Governador, mostra um padrão total de vento que é distribuído em diversas direções. No entanto, na escala anual as predominâncias foram Sudeste (SE) e Leste (E), superiores a 10\%. Mas houve ocorrência de outras direções com frequências menores, com destaque para as direções Norte $(\mathrm{N})$, Sul-sudeste (SSE) e Leste-sudeste (ESE), inferior a 10\% (Figura 2a). Verifica-se a predominância de ventos fracos com velocidade de 2 a $3 \mathrm{~m} . \mathrm{s}^{-1}$ (25\%), de 1 a 2 m.s-1 (21\%), de 3,0 a 4,0 m.s-1 $(16,6 \%)$ e de 4 a 5 m.s-1 $(10,4 \%)$, considerados brisas fracas, de acordo com a escala Beaufort. Há também ocorrência de classes de velocidade de ventos superiores a $5 \mathrm{~m} / \mathrm{s}$, por exemplo, de 5,0 a 6,0 m.s-1 (7,5\%), 6,0 a 7,0 m.s-1 (4,4\%) e 7,0 a 8,0 m.s-1 $(2,2 \%)$, ventos considerados fortes, de acordo com a escala Beaufort (WMO, 2000). A ocorrência de ventos maiores que $7,0 \mathrm{~m} \cdot \mathrm{s}^{-1}$ são equivalentes a $1,6 \%$ (Figura 2b).

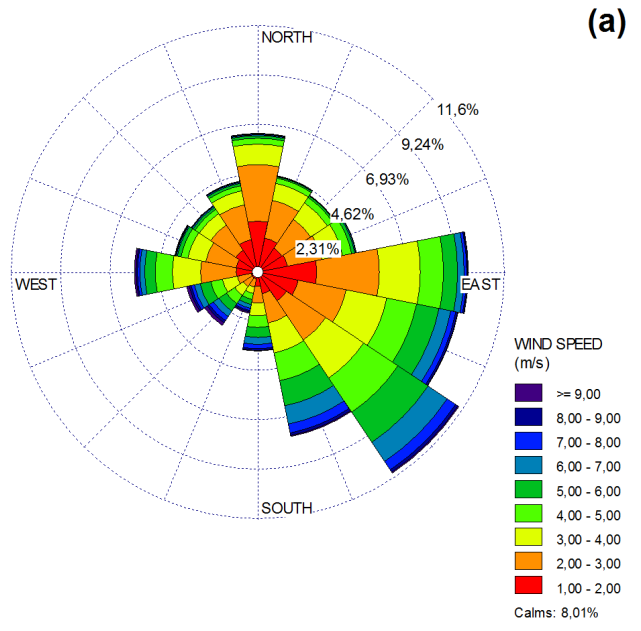

(b)

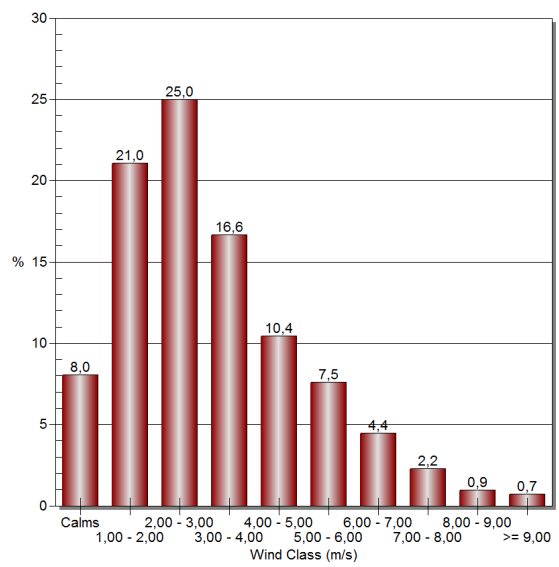

Figura 2 - Rosa dos ventos (a) e histograma (\%) das classes de velocidades do vento (m/s) (b) da Estação Meteorológica SBGL para o período 2003-2013.

Observa-se na Estação SBRJ que a direção predominante do vento é de Sul (S), com 18\%, mas também com ocorrências de outras direções $N$, sudeste (SE) e leste $(E)$, porém com frequências menores que $15 \%$. Nota-se que, em relação à Estação SBGL, a direção frequente de $S$ é devido à maior influência da circulação da brisa marítima, seguido da direção $\mathrm{N}$ correspondente a circulação de brisa terrestre, devido à maior proximidade desta com o Oceano Atlântico, resultado similar obtido por Pimentel et al. (2014) (Figura 3a). Verifica-se a predominância de ventos fracos, com velocidades de 2,0 a $3,0 \mathrm{~m} \cdot \mathrm{s}^{-1}(21,5 \%)$, 3,0 a $4,0 \mathrm{~m} \cdot \mathrm{s}^{-1}(17,2 \%), 1,0$ a $2,0 \mathrm{~m} \cdot \mathrm{s}^{-1}(17,3 \%)$ e 4,0 a $5,0 \mathrm{~m} \cdot \mathrm{s}^{-1}(11,4 \%)$, variando de brisa leve à fraca, conforme a escala Beufort (WMO, 2000). Nota-se também a ocorrência de ventos maiores que $5 \mathrm{~m} \cdot \mathrm{s}^{-1}$, entre 5 à $6 \mathrm{~m} \cdot \mathrm{s}^{-1}(7,8 \%) \mathrm{e}$ de 6,0 à $7,0 \mathrm{~m} . \mathrm{s}^{-1}(4,7 \%)$, que são ventos considerados fortes conforme a escala supracitada. A frequência total de ventos com velocidade acima de $7 \mathrm{~m} . \mathrm{s}^{-}$ 
${ }^{1}$ para essa estação foram pouco observados, com frequências menores que 3\%, comparativamente maior ao obtido para a Estação SBGL (Figura 3b).

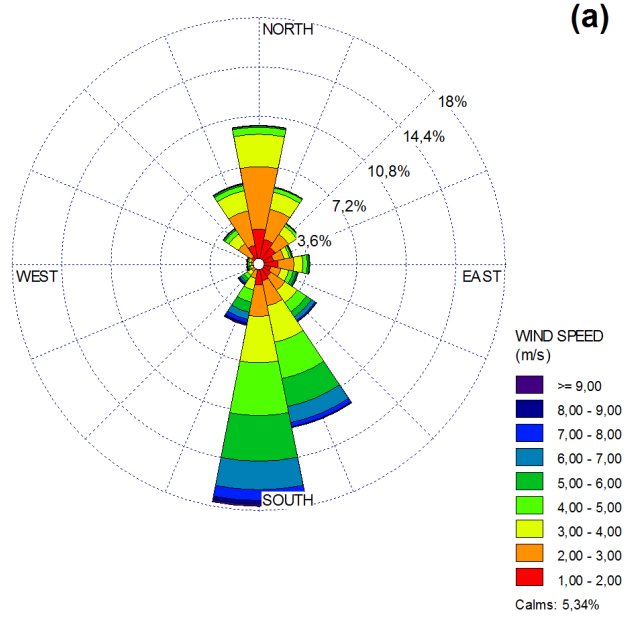

(a)

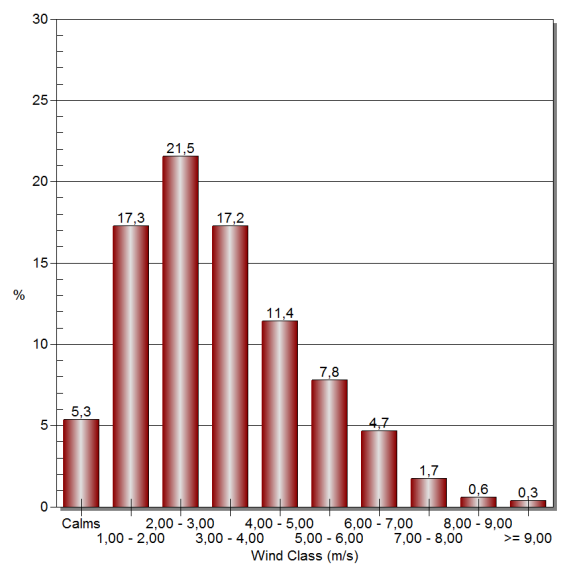

Figura 3 - Rosa dos ventos (a) e histograma (\%) das classes de velocidades do vento $\left({\left.\mathrm{m} . \mathrm{s}^{-1}\right)}^{(b)}\right.$ da Estação SBRJ para o período de 2003 a 2013.

\subsection{AVALIAÇÃO SAZONAL DO REGIME DE VENTO}

De acordo com as rosas sazonais, observa-se que as direções SE e E se mantém durante todas as estações do ano para a Estação SBGL. Nas estações de outono e inverno, observa-se uma maior frequência de ventos na direção $N$. Nos meses de verão, observa-se um aumento na frequência e na velocidade dos ventos de (E) e (SE) com um aumento significativo em suas velocidades, resultado similar obtido por Martins et al. (2004). No outono, no entanto, a velocidade dos ventos de (E) e (SE) se desintensificam. Durante a primavera, os ventos de (E) e (SE) voltam a se intensificar, porém com velocidades menores que nos meses de outono (Figura 4).

Nota-se pelos histogramas que as velocidades de vento baixas predominam durante todo o ano. No outono, a velocidade dos ventos com uma menor frequência de ventos superiores a 4,0 m.s-1 $(16,2 \%)$. Durante a primavera são observadas as maiores intensidades do vento, sendo observados maiores ocorrências de ventos com velocidades superiores a 4,0 m.s-1, igual a $34,3 \%$. No período de verão e inverno, os ventos superiores a 4,0 m.s-1 são equivalentes a 28,9 e 19,5\% dos casos (Figura 5). 


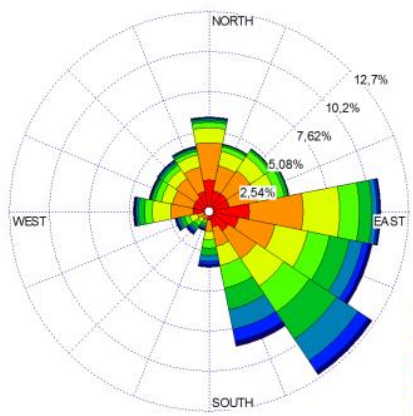

(Verão)

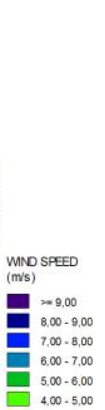

…

$2,00-3,00$
$1.00-2.00$ Caims: $6,67 \%$

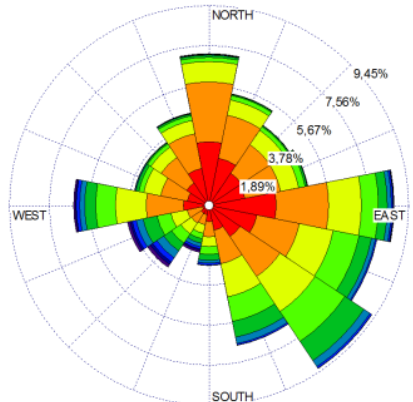

(Inverno)

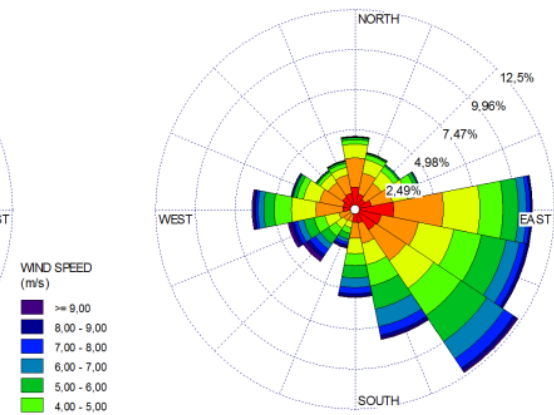

(Primavera)

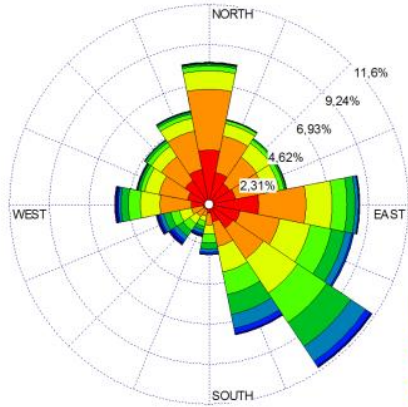

(Outono)
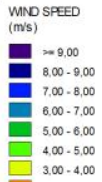

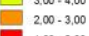

Figura 4 - Rosas dos ventos sazonais para o período de 2003 a 2013 para a Estação Meteorológica SBGL.
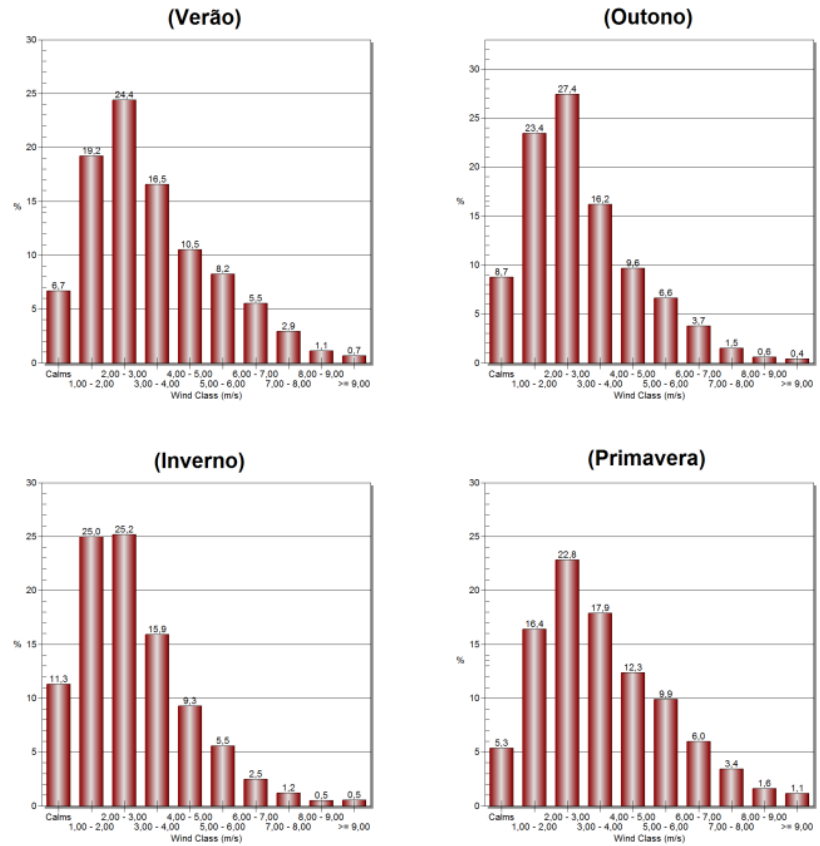

Figura 5 - Histogramas (\%) sazonais para a intensidade dos ventos (m/s) para o período de 2003-2013 na Estação Meteorológica SBGL. 
Na Estação SBRJ a direção predominante do vento é de Sul, com uma segunda predominância de Norte, principalmente no inverno. Observa-se que nos meses de verão e primavera os ventos de $\mathrm{S}$ tem uma maior predominância face às outras estações, superior a $32 \%$, supostamente devido à predominância da influência da brisa marítima para a circulação dos ventos. No período do outono e de inverno os ventos de $E$ e SE se intensificam, enquanto que os ventos de $\mathrm{S}$ apresentam uma menor redução da participação predominante. Notou-se que durante o outono há um aumento da frequência de ventos de direção N (24\%), como um padrão anômalo para a escala sazonal (Figura 6).

De acordo com os histogramas, nota-se que uma predominância geral de ventos fracos, com velocidades que variam de 1,0 a 4,0 m.s-1 para todas as estações do ano. Observa-se no verão e primavera a maior ocorrência de ventos superiores a 4,0 m.s-1, equivalente a $31,5 \%$ e $32,3 \%$, sendo novamente 0 período primaveril de maior intensidade dos ventos. A maior frequência de ventos mais intensos para a Estação SBRJ em relação à Estação SBGL sugere uma maior influência da brisa marítima para a intensificação dos ventos na área de estudo. O outono é a estação do ano com a menor frequência de ventos superiores a 4,0 m.s-1 (23,9\%) e, em seguida, o inverno apresenta $26,6 \%$ da intensidade superior à referida acima (Figura 7).

Os principais sistemas meteorológicos que atuam no Rio de Janeiro variam da escala sinótica à local, sendo eles: os Sistemas Frontais (SF), os Complexos Convectivos de Mesoescala (CCM), a Zona de Convergência do Atlântico Sul (ZCAS), o Anticiclone Subtropical do Atlântico Sul (ASAS), os Bloqueios Atmosféricos (BA) e os sistemas de brisas (vale/montanha, lacustre e marítima/terrestre), sendo que os sistemas de brisas influenciam os eventos meteorológicos, chuvas orográficas e tempestades convectivas (REBOITA et al., 2010; OLIVEIRA JÚNIOR et al., 2014; BRITO et al., 2016). Estes sistemas modificam a estrutura da circulação e as próprias condições de tempo local e em regiões adjacentes, principalmente nas Baías de Sepetiba e Guanabara (MORAES et al., 2005; ZERI et al., 2011; OLIVEIRA JÚNIOR et al., 2013). 

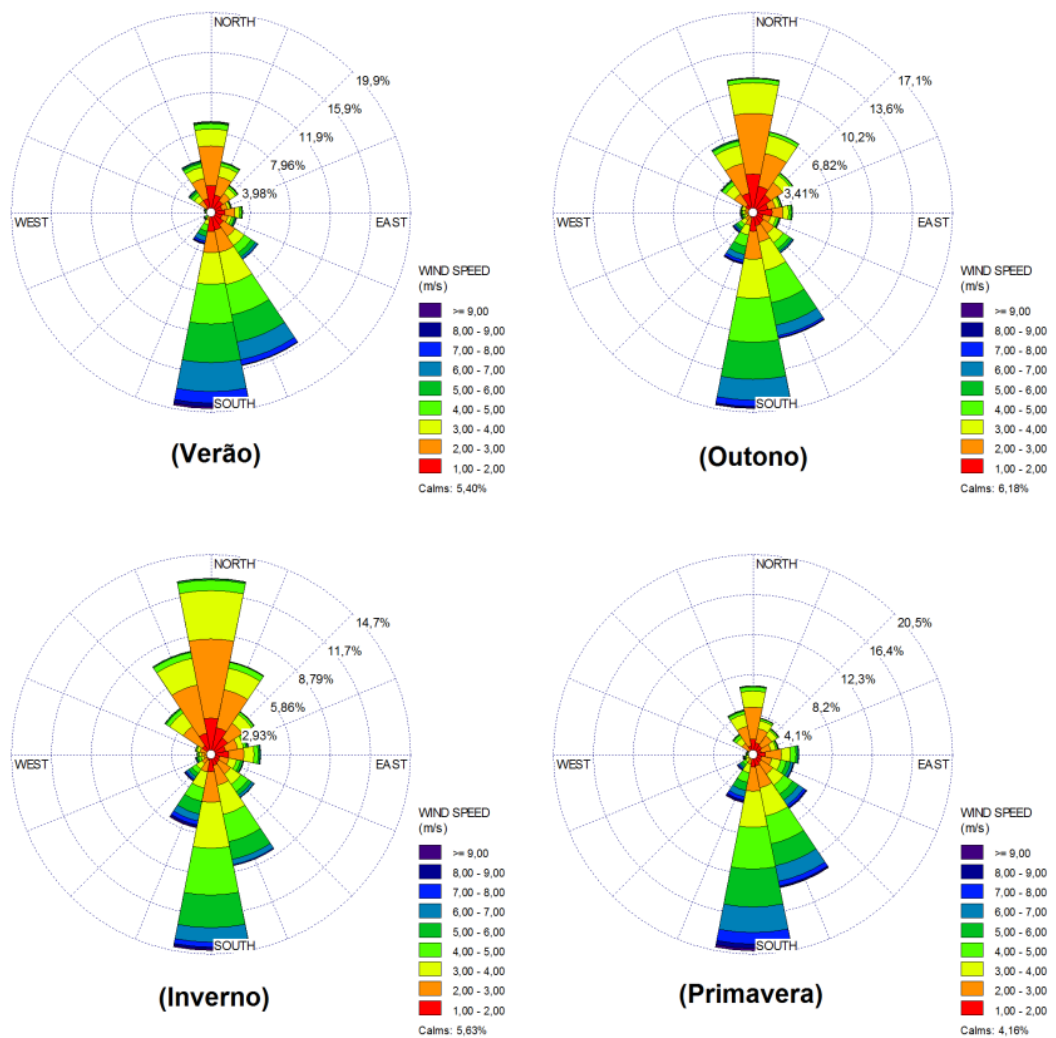

Figura 6 - Rosas dos ventos sazonais para o período de 2003 a 2013 para a Estação Meteorológica SBRJ.
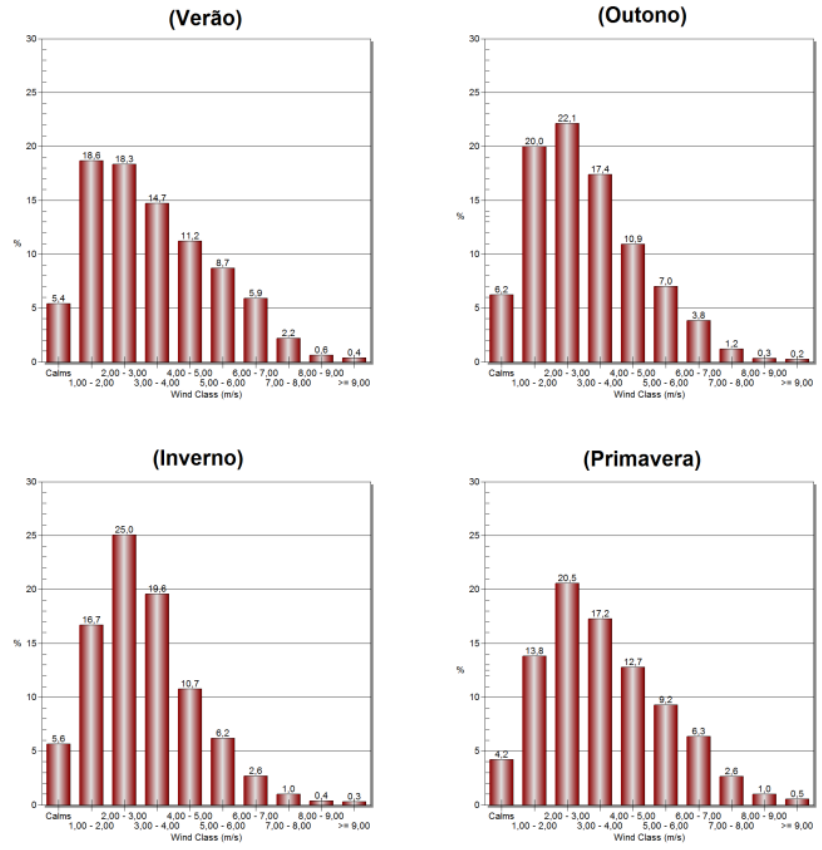

Figura 7 - Histogramas (\%) sazonais para a intensidade dos ventos (m.s-1) para o período de 2003-2013 na Estação Meteorológica SBRJ. 


\subsection{AVALIAÇÃo CÍCLICA DO REGIME DE VENTO}

De acordo com as rosas dos ventos para a Estação SBGL, infere-se que no período da madrugada (00h-06h) os ventos apresentam um padrão dominante $\mathrm{E}$ e $\mathrm{SE}$, superior a $18 \%$ para ambas as direções, mas podemos observar que outras direções de vento também ocorrem, porém com menos frequência. No período da manhã (06h-12h), observa-se que ocorre um giro no vento, que passa a ser predominantemente de $\mathrm{N}(>18 \%)$. Durante a tarde (12h-18h), observa-se um novo giro do vento, predominantemente de SE (30\%), embora as direções $E, N E, N$ e $S$ também são observadas, mas com uma intensidade bem menor frente aos ventos SE. Durante a noite (18h-23h) não ocorre giro do vento, os ventos $N$, NE se desintensificam e os ventos de $E$ tornam-se ligeiramente mais fortes ( $>28 \%$ ). Observa-se também que os ventos $\mathrm{SE}$ enfraquecem. Esses giros na direção cíclica da direção dos ventos se devem a ocorrência das circulações de brisas marítimas e terrestre, similar ao encontrado por Oliveira Júnior et al. (2013) e Pimentel et al. (2014) (Figura 8).

Os dados da Estação SBGL mostram que durante a madrugada (00h06h) e a manhã (00h-12h) predominam velocidades de vento mais baixas variando de 1,0 a 3,0 m.s-1, superiores a $60 \%$ e nota-se que acontecem mais frequentemente as calmarias $(>14 \%)$, demonstrando que as brisas terrestres são mais fracas que as marítimas. Durante a tarde ( $12 \mathrm{~h}-18 \mathrm{~h})$, observa-se um grande aumento nos padrões de velocidade do vento com um grande aumento na frequência de ventos com velocidades acima de 4,0 m.s-1 (47,8\%), evidenciando que a brisa marítima é mais intensa que a brisa terrestre. Durante a noite (18h-23h), observa-se um declínio nas velocidades do vento em relação ao período citado anteriormente, com reduções mais significativas nas classes de intensidade dos ventos superiores a 6,0 m.s-1 (Figura 9). 

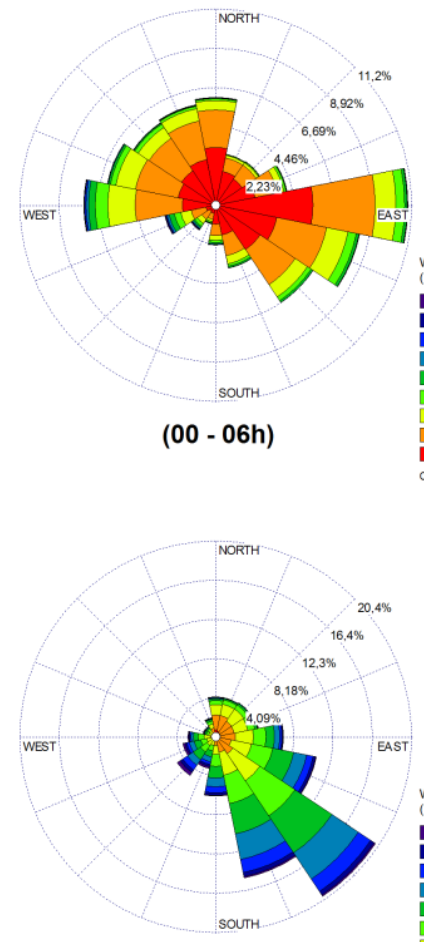

$(12-18 h)$

4.000.5,00

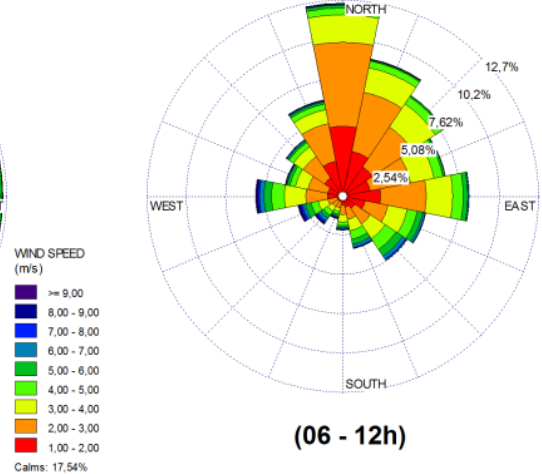

$(06-12 h)$

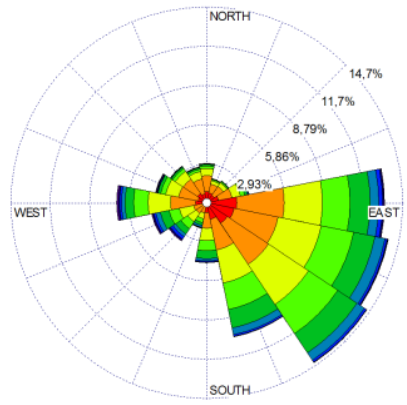

$(18-23 h)$
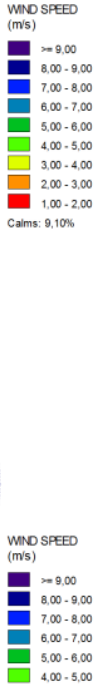
$2,00-3.00$
$1,00 \cdot 2,00$

Figura 8 - Rosas cíclicas dos ventos para o período de 2003 a 2013 na Estação Meteorológica SBGL.
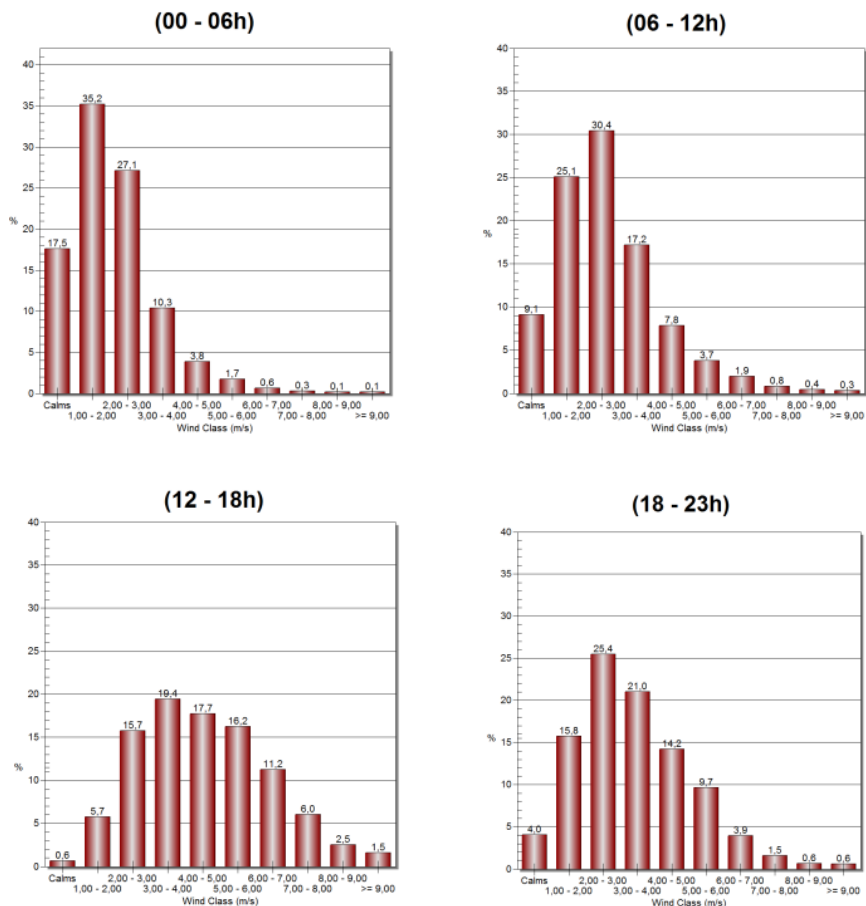

Figura 9 - Histogramas (\%) cíclicos dos ventos para o período de 2003 a 2013 na Estação Meteorológica SBGL. 
As rosas dos ventos para a Estação SBRJ demonstram que no período da madrugada (00h-06h) e da manhã (06h-12h) o padrão dominante de ventos é de $\mathrm{N}$, superior a $24 \%$ e $32 \%$, respectivamente, demonstrando a prevalência de ventos oriundos do continente para o ambiente costeiro. No período da tarde (12h-18h) observa-se um giro do vento para a direção (S), com valores superiores a $52 \%$, o que mostra que nitidamente a atuação da brisa marítima na circulação dos ventos. Durante a noite (18h-23h) observa-se que os ventos de $\mathrm{S}(32 \%)$ se enfraquecem confirmando que a brisa marítima começa a se enfraquecer para que após novo giro do vento a brisa terrestre passe a atuar (Figura 10).

Observa-se que no período da madrugada (00h-06h) predominam as velocidades mais baixas variando de 1,0 a 4,0 m.s-1 $(80,5 \%)$ e observa-se também a presença significativa de calmarias (14,6\%). Durante a manhã (06h$12 \mathrm{~h}$ ) o padrão de velocidades do vento é muito semelhante ao da madrugada, com um aumento nas velocidades do vento acima de 4,0 m.s ${ }^{-1}(18,4 \%)$ e uma redução nas calmarias $(5,7 \%)$. No período da tarde (12h-18h), no entanto, observa-se um grande aumento nas velocidades do vento acima de 4,0 m.s-1 $(63,6 \%)$, com um padrão de ventos mais forte e a diminuição mais significativa na frequência de calmarias $(1,4 \%)$. Durante a noite $(18 \mathrm{~h}-23 \mathrm{~h})$ a velocidade dos ventos diminui, com um decréscimo na frequência de ventos com velocidade acima de 4,0 m.s-1 (26,6\%), mostrando que a brisa marítima se enfraquece durante esse período até diminuir gradativamente até o período da madrugada (Figura 11).

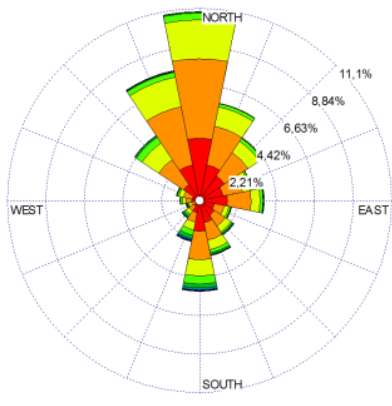

(00 - 06h)

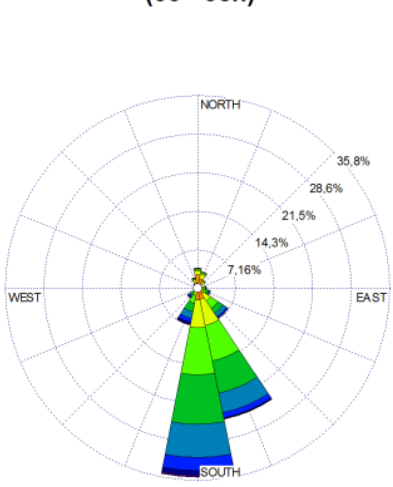

(12 - 18h)

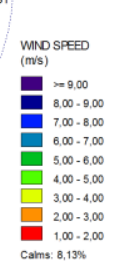

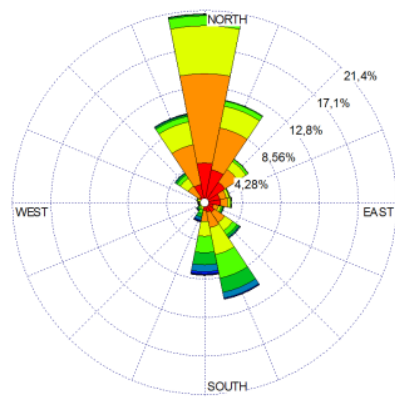

(06 - 12h)
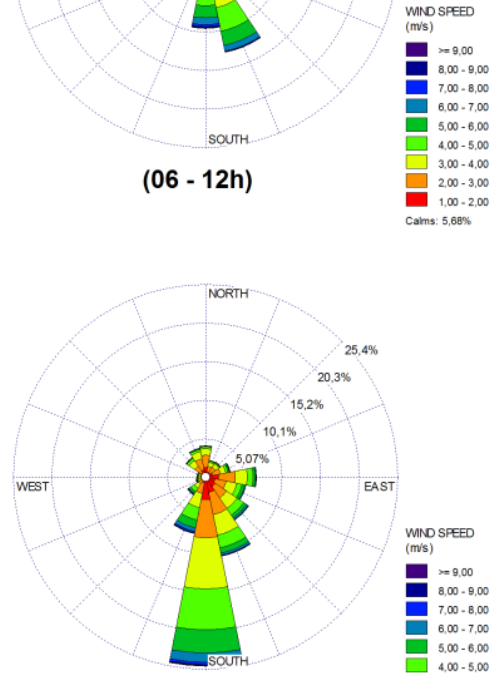

(18 - 23h)

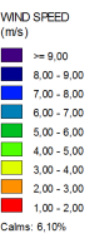

Figura 10 - Rosas cíclicas dos ventos para o período de 2003 a 2013 na Estação Meteorológica SBRJ. 


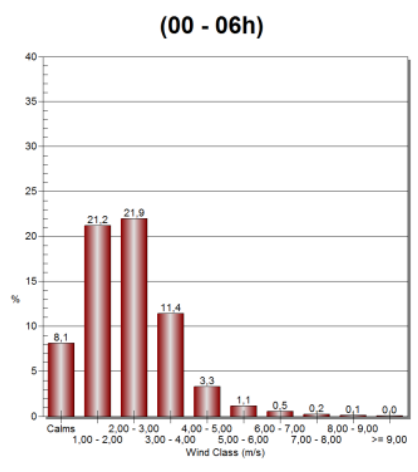

$(12-18 h)$

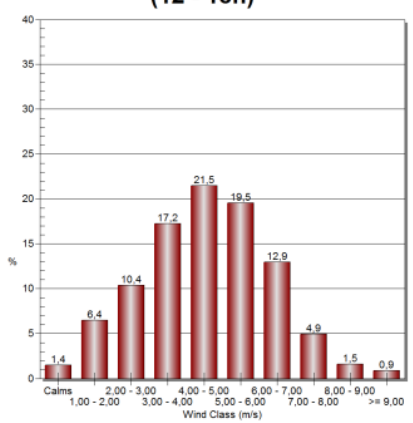

$(06-12 \mathrm{~h})$

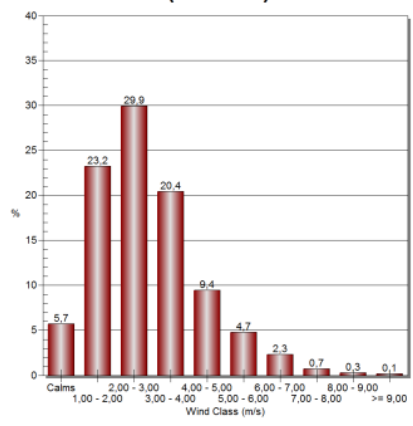

$(18-23 h)$

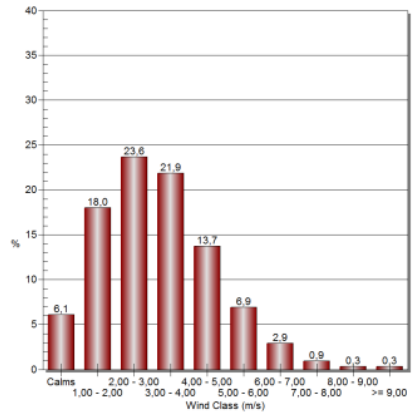

Figura 11 - Histogramas (\%) cíclicos dos ventos para o período de 2003 a 2013 na Estação Meteorológica SBRJ.

\subsection{ESTATÍSTICA EXPLORATÓRIA APLICADA À SÉRIE TEMPORAL DO VENTO}

Mostra-se que a velocidade mensal da Estação SBGL apresentou alta

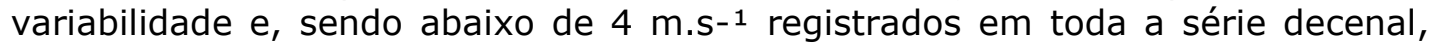
sendo os meses de maio, junho e julho com os menores valores da velocidade média na escala decenal, abaixo de 3,0 m.s-1. As velocidades médias mensais do vento na Estação SBRJ revelaram valores próximos de 3,0 m.s-1, porém observa-se uma maior variabilidade e maiores valores da velocidade dos ventos entre agosto e dezembro, resultados semelhantes aos obtidos por Silva et al. (1997), Galvani et al. (1999), Munhoz e Garcia (2008) e Oliveira Júnior et al. (2013), Morais et al. (2014) para as localidades de Pelotas (RS), Maringá (PR), Ituverava (SP), Seropédica (RJ) e Mossoró (RN) o que se atribui à intensificação dos ventos alísios e à aproximação do centro de ação do ASAS (Figura 12).

O regime médio da velocidade do vento na região da Baía de Guanabara se modifica ao longo do ano, em virtude dos pontos da área de estudo estarem no fundo da Baía, na Ilha do Governador, e com a influência da Serra dos Órgãos. Por sua vez, a Estação SBRJ caracteriza-se pela menor velocidade dos ventos por estar próximo à área densamente urbanizada da cidade (MORAES et al., 2005; OLIVEIRA-JÚNIOR et al., 2015). Os valores extremos (outliers) foram identificados nas estações do SBGL e SBRJ, principalmente nos meses de fevereiro, maio, junho, novembro e dezembro (Figura 12).

Sazonalmente, ocorre uma variação das velocidades médias, entre 2,5 e 3,5 m.s-1, classificado como brisa leve segundo WMO (WMO, 2000) - (Figura 
12), principalmente nas estações de transição (outono e primavera), na Estação SBGL. Isso se deve à ocorrência da circulação de brisa marítima/terrestre acoplado ao regime de circulação de ventos na Baía de Guanabara, denominado de brisa de Baía, juntamente com a entrada de SF e a sua interação com Serra dos Órgãos (BRITO et al., 2016). Na Estação da SBRJ mostrou alteração do padrão de intensidade do vento médio, a partir do mês de agosto similar a estação SBGL. Ou seja, mostrou-se influência da passagem de SF e o posicionamento e migração do ASAS em ambas as estações.
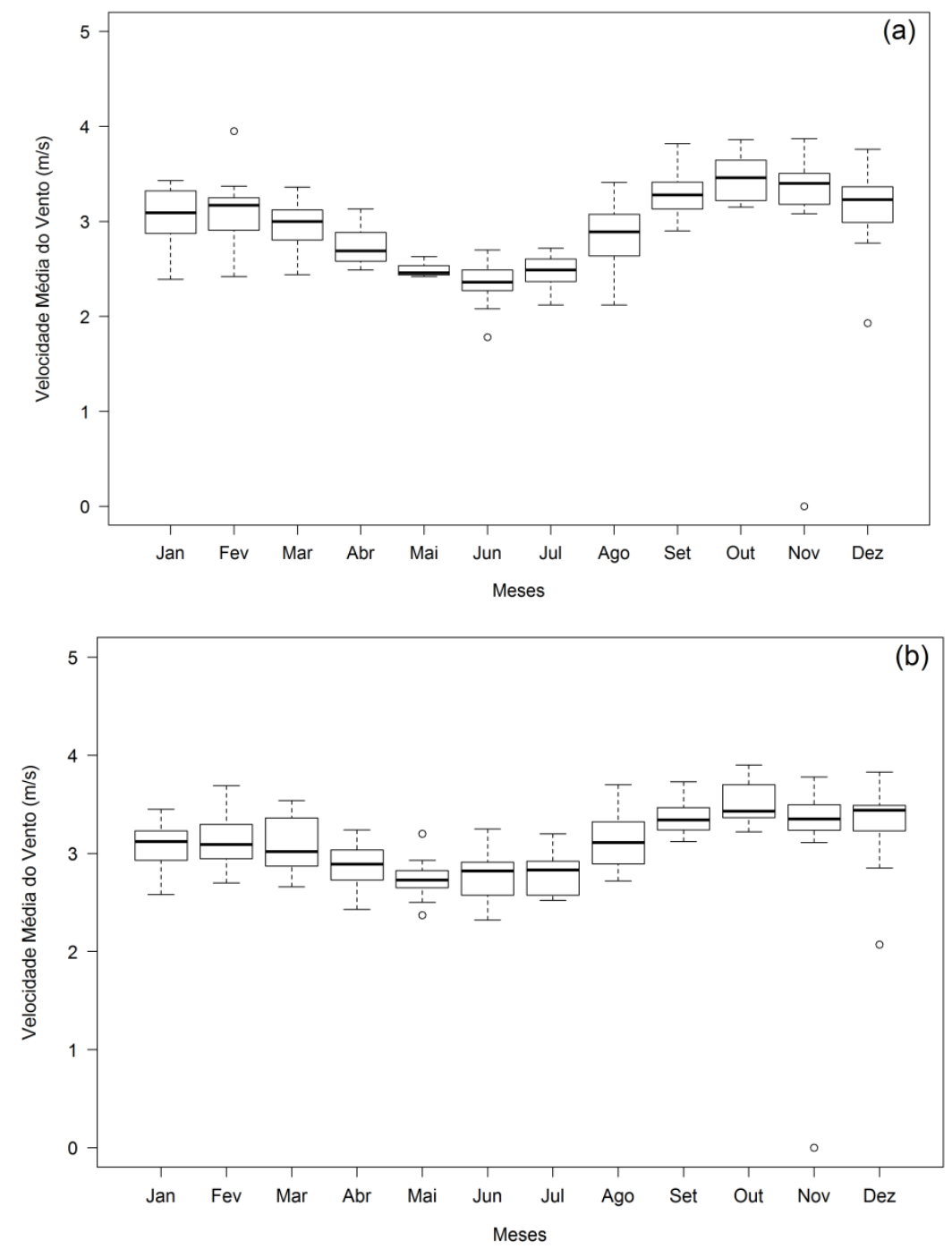

Figura 12 - Boxplot da velocidade média mensal (m.s-1) das Estações Meteorológica SBGL (a) e SBRJ (b) para o período de 2003 a 2013.

Baseando-se no teste Run mostraram que a série temporal de vento anual da estação do Galeão, pode ser considerada livre de correlação serial ou persistência temporal, tendo como exceções os anos de 2005, 2006 e 2009, associado a um p-valor de 0,0154. Os demais valores de zcal encontram-se entre o valor crítico de $z(-1,96$ a $+1,96)$ estabelecido, com um p-valor de 
0,2259. Por sua vez, a Estação Santos Dumont mostrou apenas os anos de 2005 e 2009, respectivamente, que não podem ser considerados livres de correlação serial ou persistência temporal. Visto que os valores de zcal encontram-se abaixo do limite crítico de $z(-1,96)$ para um $p$-valor de 0,0154 , e os demais valores de zcal dentro do valor crítico de $z(-1,96$ a $+1,96)$ com um $p$-valor de 0,5448 . Entretanto, em ambas as estações foram encontradas baixos valores do teste Run ( 2 a 8 ) que indicam desvio abaixo da mediana durante o período de estudo (Figura 13).
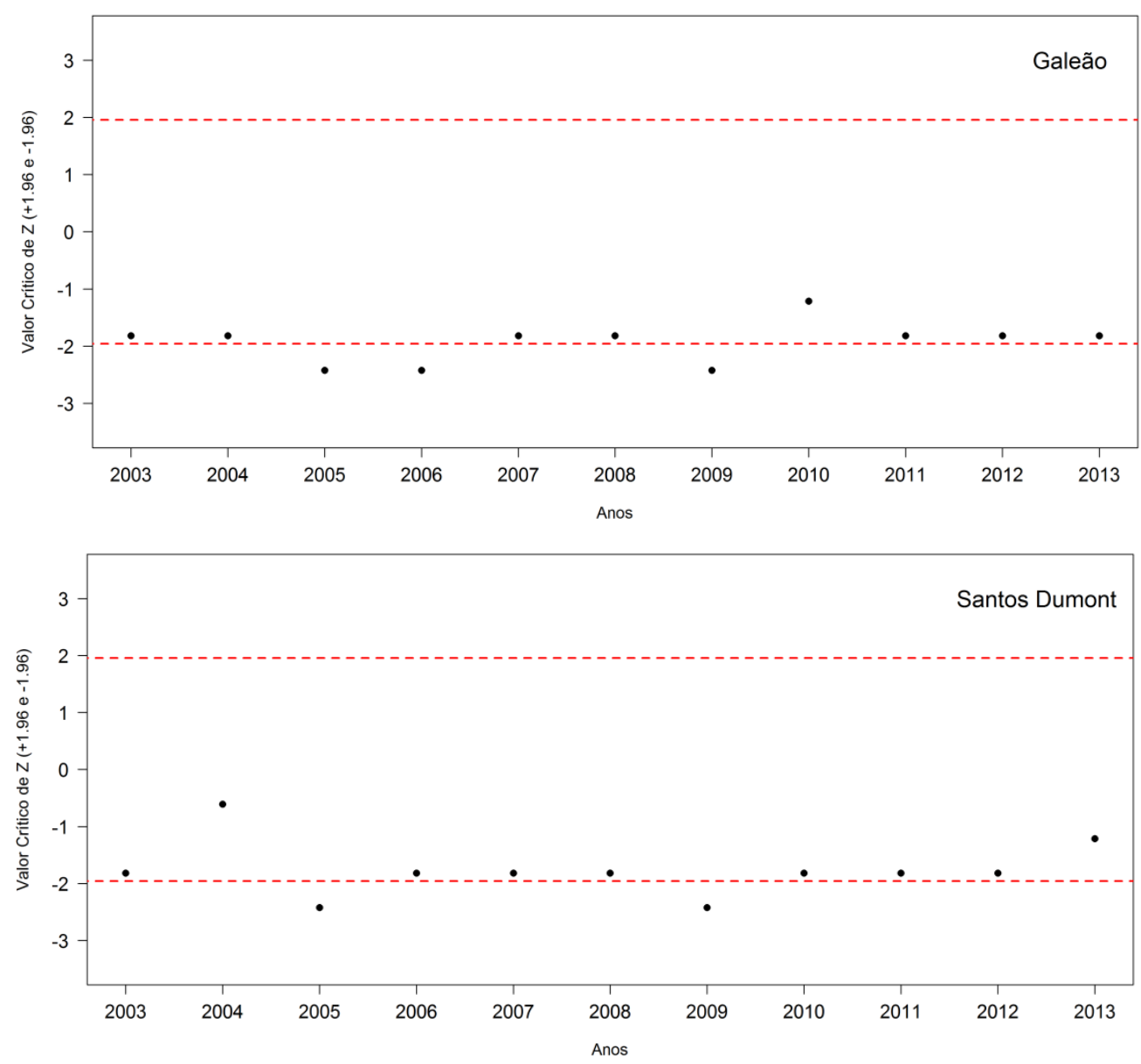

Figura 13 - Valores anuais do vento baseado no teste Run entre o período de 2003 a 2013, aplicado às estações do Galeão e Santos Dumont.

\subsection{INFLUÊNCIA DOS SISTEMAS SINÓtICOS NA CIRCULAÇÃO DE VENTO NA BAÍA DE GUANABARA}

A partir do teste Run foram identificados os anos de 2005, 2006 e 2009 em ambas as estações, que apresentam correlação serial. Neste estudo de caso foi avaliada a influência dos sistemas sinóticos na direção e velocidade do vento nos anos supracitados, que se repetiram nas estações do SBGL e SBRJ, com base nos boletins climatológicos da Climanálise (CLIMANÁLISE, 2017).

Verifica-se que ocorreu alta variabilidade de sistemas sinóticos atuante na região Sudeste, com destaque para atuação do ASAS no Rio de Janeiro, 
sendo de forma permanente. O ASAS têm predominância de ventos no quadrante $N$ (N, NE e NNE), seguido da sua posição migratória e de fraca intensidade (CORRÊA et al., 2006; ZERI et al., 2011). Ressalta-se que na contagem via boletins mensais apenas na estação de inverno na região Sudeste houve destaque com 5 casos (14\%) juntamente com SF.

Outro sistema que atua frequentemente no Rio de Janeiro é o SF, ora de forma isolada ( 9 casos, $25 \%$ ) ou de forma conjunta ( 26 casos, $72 \%$ ), conforme a tabela 5. As direções W, S e SW referem-se à atuação da circulação da brisa da Baía, seguida da ocorrência da passagem de SF na região (SW) - (CORRÊA et al., 2006; DERECZYNSKI et al., 2009; OLIVEIRA JÚNIOR et al., 2013). No entanto, quando o SF ocorre de forma conjunta com outro sistema sinótico produz giro do vento em diversas direções, sendo identificado nas escalas sazonais e cíclicas, mostradas anteriormente. A ZCAS é um sistema sinótico que ocorre nas estações de verão e primavera (BRITO et al., 2016). Ela que pode ocorrer isolado (1 caso, 3\%) ou de forma conjunta (14 casos, 39\%), similar ao SF. Outros sistemas sinóticos (VCAN, VCANs e JBN - 12 casos, 33\%) apareceram no estudo de caso, no entanto, sempre de forma conjunta com os SF e ZCAS. Eles também influenciam no regime de vento na região de estudo.

Tabela 5 - Distribuição dos sistemas meteorológicos que atuaram na região Sudeste nos anos de 2005, 2006 e 2009, respectivamente.

\begin{tabular}{l|c|c|c|c|c|c|c|c|c|c|c|c}
\hline \multirow{2}{*}{$\frac{\mathbb{U}}{\Sigma}$} & $\mathbf{J}$ & $\mathbf{A}$ & $\mathbf{M}$ & $\mathbf{A}$ & $\mathbf{M}$ & $\mathbf{J}$ & $\mathbf{J}$ & $\mathbf{A}$ & $\mathbf{S}$ & $\mathbf{O}$ & $\mathbf{N}$ & $\mathbf{D}$ \\
$\mathbf{N}$ & $\mathbf{V}$ & $\mathbf{A}$ & $\mathbf{R}$ & $\mathbf{A}$ & $\mathbf{U}$ & $\mathbf{U}$ & $\mathbf{G}$ & $\mathbf{E}$ & $\mathbf{U}$ & $\mathbf{O}$ & $\mathbf{E}$ \\
$\mathbf{I}$ & $\mathbf{N}$ & $\mathbf{L}$ & $\mathbf{O}$ & $\mathbf{T}$ & $\mathbf{T}$ & $\mathbf{V}$ & $\mathbf{Z}$ \\
\hline $\mathbf{2 0 0 5}$ & $1-2$ & $1-2$ & $1-2$ & $1-4$ & 1 & $1-3$ & $1-3$ & $1-3$ & 1 & 1 & $1-5$ & $1,2-5$ \\
$\mathbf{2 0 0 6}$ & $1,2-5$ & $1-2$ & $1-2$ & 1 & $1-6$ & $1-5$ & $1-5$ & $1-3$ & 1 & $1,2-4$ & 1 & $1-2$ \\
$\mathbf{2 0 0 9}$ & 2 & $1-2$ & $1-2$ & 1 & $1-4$ & $1-3$ & $1-3$ & $1-5$ & 1 & $1-2$ & $1,2-5$ & $1,2-5$
\end{tabular}

Legenda: 1 - SF, 2 - ZCAS, 3 - ASAS, 4 - Vórtices e Cavados em Alto níveis (VCANs), 5 - Vórtices Ciclônico em Alto Níveis (VCAN), 6 - Jatos em Baixos Niveis (JBN).

\section{CONSIDERAÇÕES FINAIS}

Com base na estatística exploratória mostra-se que as velocidades médias mensais da Estação SBGL apresentaram alta variabilidade, não ocorrendo na Estação SBRJ, com exceção do mês de novembro. A velocidade de média da Estação SBGL demonstrou uma maior influência conjugada da circulação de brisa marítima acoplado ao regime de circulação de ventos na Baía de Guanabara, juntamente com a entrada de sistemas frontais e a sua interação com Serra dos Órgãos. Na Estação SBRJ não se mostrou alteração do padrão de intensidade do vento médio, o que se atribui a uma menor atuação de outras forçantes, tais como a orografia e a passagem de sistemas frontais.

O teste Run aplicado à série temporal de vento anual é considerado livre de correlação serial ou persistência temporal nas estações SBGL e SBRJ, as exceções são nos anos de 2005, 2006 e 2009, respectivamente. De modo geral, 
o teste de sequência indica que a série temporal anual de vento na Baía de Guanabara é aleatória e está dentro da normalidade.

A direção dos ventos para a escala anual na Estação SBGL são predominantes nas direções SE e $L$, enquanto a Estação SBRJ, com maior influência da brisa marítima, devido à maior proximidade do ambiente costeiro, a direção é de $S$, sendo que em ambas predominaram os ventos de intensidade entre 1,0 a 4,0 m.s- ${ }^{-1}$.

Na escala sazonal, a direção predominante dos ventos na Estação SBGL continua sendo SE e $L$, enquanto que a Estação SBRJ apresenta uma intensificação da direção do vento $S$, superior a $32 \%$, no verão e na primavera, devido maior influência da circulação da brisa marítima. Entretanto, durante o outono e inverno, com a atuação do ASAS, ocorre um aumento dos ventos oriundos de NE e L. Para ambas as estações a intensidade dos ventos é maior na primavera e no verão.

O padrão cíclico diário de direção dos ventos na Estação SBRJ recebe a influência da circulação da brisa marítima em relação à Estação SBGL, uma vez que durante o período das $00 \mathrm{~h}-06 \mathrm{~h}$ e $06 \mathrm{~h}-12 \mathrm{~h}$ predominam os ventos $\mathrm{N}$, na direção do continente para a costa, e para os ciclos das $12 \mathrm{~h}-18 \mathrm{~h}$ predominam os ventos de direção $S$, do oceano para o continente, com uma redução significativa entre $18 \mathrm{~h}$ às $23 \mathrm{~h}$. Para a Estação SBGL, observa-se o predomínio das direções E e SE durante o ciclo das 00h-06h, direção N entre 06h-12h e direção $E$ e SE para os demais períodos do dia. Os maiores registros de calmarias são observados na Estação SBGL, entre os horários das 00h-06h e $06 \mathrm{~h}-12 \mathrm{~h}$, superiores a $14 \%$ e o período de maior intensidade dos ventos, com valores maiores que 4,0 m.s-1 foram identificados para a Estação SBRJ durante o ciclo das $12 \mathrm{~h}-18 \mathrm{~h}$, isso demostra a influência da brisa marítima na circulação dos ventos nos arredores da Baía de Guanabara.

\section{AGRADECIMENTOS}

Os autores agradecem ao INMET, INPE e a REDEMET pela disponibilidade dos dados meteorológicos e dos boletins mensais climatológicos da Climanálise. O primeiro autor agradece ao Conselho Nacional de Pesquisa (CNPq) pela concessão da Bolsa de Produtividade de Pesquisa (processo n0306410/2015-0). O segundo e o terceiro autor agradecem a Coordenação de Aperfeiçoamento de Pessoal de Nível Superior (CAPES) pela concessão da Bolsa de Doutorado e PósDoutorado, respectivamente.

\section{REFERÊNCIAS BIBLIOGRÁFICAS}

ABBS, D. J.; PHYSICK, W. L. Sea breeze observations and modeling: a review. Australian Meteorological Magazine, Melbourne, v.41, n.1, p.7-19, 1992.

ÁlVARES, C. A.; STAPE, J. L.; SENTELHAS, P. C.; DE MORAES GONÇALVES, J.L.; SPAROVEK, G. Köppen's climate classification map for Brazil. Meteorologische Zeitschrift, Berlin, v.22, n.6, p.711-728, 2013.

ARRITT, R. A. Numerical modeling of the offshore extent of the sea breezes. Quarterly Journal of the Royal Meteorological Society, Oxford, v.115, n.1, p.647570, 1989. 
ATKINSON, B.W. Mesoscale Atmospheric Circulations. $1^{\text {a }}$ ed., New York City, Academic Press, 1981.

BACK, A. Aplicação de análise estatística para identificação de tendências climáticas. Pesquisa Agropecuária Brasileira, Brasília, v.36, n.5, p.717-726, 2001.

BONNARDOT, V.; PLANCHON, O.; CAUTENET, S. Sea breeze development under an offshore synoptic wind in the South-Western Cape and implications for the Stellenbosch wine-producing area. Theoretical and Applied Climatology, Berlin, v.81, n.3, p.203-218, 2005.

BRITO, T. T.;OLIVEIRA JÚNIOR, J. F.; LYRA, G. B.;GOIS, G.; ZERI, M. Multivariate analysis applied to monthly rainfall over Rio de Janeiro state, Brazil. Meteorology and Atmospheric Physics (Print), Berlin, v.1, p.1-10, 2016.

CLIMANÁlISE. Produtos Climanálise INPE/CPTEC. 2017. Disponível em: <www.cptec.inpe.br/products/climanalise>. Acesso em 19 de julho de 2017.

CORRÊA, E. B.; CATALDI, M.; PIMENTEL, L. C. G. Análise comparativa das simulações do modelo de mesoescala MM5 e dados meteorológicos observados para a região do Galeão/RJ. Anuário do Instituto de Geociências (UFRJ), Rio de Janeiro, v.29, n.2, p.66-86, 2006.

DEFANT, F. Local Winds. In: Compendium of Meteorology. Boston: American Meteorological Society, p.655-672, 1951.

DERECZYNSKI, C.P., OLIVEIRA, J.S., MACHADO, C.O. Climatologia da precipitação no Município do Rio de Janeiro. Revista Brasileira de Meteorologia, São Paulo, v.24, n.1, p.24-38, 2009.

ESTOQUE, M.A. The sea breeze as a function of the prevailing synoptic situation. Journal Atmospheric Science, Boston, v.19, n.3, p.244-250, 1962.

GALVANI, E.; KLOSOWSKI, E.S.; CUNHA, A. R.; MARTINS, D. Caracterização da direção predominante do vento em Maringá-PR. Revista Brasileira de Agrometeorologia, Santa Maria, v.7, n.1, p.81-90, 1999.

KÖPPEN, W. Das geographische System der Klimate. In: KÖPPEN, W., GEIGER, R. Handbuch der Klimatologie. Berlin: Gebrüder Borntraeger, p.1-44, 1936.

LYRA, G.B.; ODA-SOUZA, M.; VIOLA, D.N. Modelos Lineares aplicados à estimativa da concentração do material particulado $\left(\mathrm{PM}_{10}\right)$ na cidade do Rio de Janeiro, RJ. Revista Brasileira de Meteorologia, São Paulo, v.26, n.3, p.392-400, 2011.

LAKES ENVIRONMENTAL SOFTWARE. Wind Rose Plots For Meteorological Data WRPLOT View. 2017. Disponível em: <http://www.weblakes.com/products/wrplot/index.html.>. Acesso em $20 \mathrm{de}$ março de 2017.

MARTINS, N.S.F., MARQUES, F.A., SILVA CUNHA, A.E., MAIA, L.F.P.G. Indicações Observacionais de Ocorrências de Brisas Marítimas na Cidade do Rio de Janeiro. In: XIII Congresso Brasileiro de Meteorologia, Fortaleza, p.1-10, 2004

MORAES, M. S. Modelagem do Mecanismo de Formação e Desintensificação de ilha de calor na Região Metropolitana do Rio de Janeiro. 2008. 113 f. Dissertação 
(Mestrado). Programa de Pós-Graduação em Engenharia, Universidade Federal do Rio de Janeiro, Rio de Janeiro, 2008.

MORAES, N.O.; MARTON, E.; PIMENTEL, L.C.G. Simulações numéricas da formação de ilha de calor na Região Metropolitana do Rio de Janeiro. Anuário do Instituto de Geociências, Rio de Janeiro, v.28, n.2, p.116-138, 2005.

MORAIS, G.M.; SOBRINHO, J.E.; SANTOS, W.O.; COSTA, D.O.; SILVA, S.T.A.; MANIÇOBA, R.M. Caracterização da velocidade e direção do vento em Mossoró/RN. Revista Brasileira de Geografia Física, Recife, v.7, n.4, p.746-754, 2014.

MUNHOZ, F.C.; GARCIA, A. Caracterização da velocidade e direção predominante dos ventos para a localidade de Ituverava - SP. Revista Brasileira de Meteorologia, São Paulo, v.23, n.1, p.30-34, 2008.

NEUMANN, J. The sea and land breeze in the classical Greek literature. Bulletin American Meteorological Society, Boston, v.54, n.1, p.5-8, 1973.

OLIVEIRA JÚNIOR, J.F.; SOUZA, J.C.S.; DIAS, F.O.;GOIS, G.;GONCALVES, I. F. S.;SILVA, M.S. Caracterização do Regime de Vento no Município de Seropédica, Rio de Janeiro (2001-2010). Floresta e Ambiente, Seropédica, v.20, n.4, p. 447459, 2013.

OLIVEIRA JÚNIOR, J. F.; DELGADO, R. C.;GOIS, G.; LANNES, A. ;DIAS, F. O.; SOUZA, J. C. S.; SOUZA, M. Análise da Precipitação e sua Relação com Sistemas Meteorológicos em Seropédica, Rio de Janeiro. Floresta e Ambiente, v.21, n.2, p.140-149, 2014.

OLIVEIRA JÚNIOR, J. F.;LYRA, G. B.; SPERANDIO, L. Modelos de Zolnier e Campbell-Norman para estimativa da temperatura do ar no Rio de Janeiro. Revista Brasileira de Engenharia Agrícola e Ambiental (Online), João Pessoa, v.19, n.8, p.727-733, 2015.

PIELKE, R.A. A three-dimensional numerical model of the sea breeze over South Florida. Monthly Weather Review, Boston, v.102, n.2, p.115-139, 1974.

PIMENTEL, L. C. G.; MARTON, E.; SILVA, M. S.; JOURDAN, P. Caracterização do regime de vento em superfície na Região Metropolitana do Rio de Janeiro. Revista de Engenharia Sanitária e Ambiental, Rio de Janeiro, v.19, n.2, p. 121132, 2014.

PRABHA, T.V.; VENKATESAN, R.; MURSCH-RADLGRUBER, E.; RENGARAJAN, G.; JAYANTHI, N. Thermal internal boundary layer characteristics at a tropical coastal site as observed by a mini-SODAR under varying synoptic conditions. Earth Planet Science, Bengaluru, v.111, n.1, p.63-77, 2002.

R DEVELOPMENT CORE TEAM. R: A language and environment for statistical computing. R Foundation for Statistical Computing, Vienna, Austria. ISBN 3900051-07- 0, URL http://www.R-project.org. 2016.

REBOITA, M.S.; GAN, M.A.; ROCHA, R.P., AMBRIZZI, T. Regimes de Precipitação na América do Sul: Uma Revisão Bibliográfica. Revista Brasileira de Meteorologia, São Paulo, v.25, n.2, p.185-204, 2010.

REDEMET (Rede de Meteorologia do Comando da Aeronáutica). Sistema de Geração e Disponibilização de Informações Climatológicas. Disponível 
em: <www.redemet.aer.mil.br/index.php?i=produtos\&p=site-clima $>$. Acesso em 19 de julho de 2017.

SANTOS, T.C.; CARVALHO, V.S.B; REBOITA, M.S. Avaliação da influência das condições meteorológicas em dias com altas concentrações de material particulado na Região Metropolitana do Rio de Janeiro. Revista de Engenharia Sanitária e Ambiental, Rio de Janeiro, v.21, n.2, 307-313, 2016.

SILVA, J.B.; ZANUSSO, J.F.; SILVEIRA, D.L.M. Estudo da velocidade e direção dos ventos em Pelotas, RS. Revista Brasileira de Agrometeorologia, Santa Maria, v.5, n.2, p227-235, 1997.

SIMPSON, J. E. Sea breeze and local winds. Cambridge: Cambridge University Press, 1994. 234p.

STIVARI, S.M.S.; OLIVEIRA, A.P.; KARAM, H.A.; SOARES, J. Patterns of Local circulations in the Itaipu lake area: numerical simulations of lake breeze. Journal of Applied Meteorology, Boston, v.42, n.1, p.37-50, 2003.

TAYT-SOHN, F.C.O., MORAES, N.O., MARTON, E., PIMENTEL, L.C.G. Estudo da influência dos efeitos da brisa marítima sobre a ilha de calor urbana na Região Metropolitana do Rio de Janeiro utilizando o Modelo MM5. In: XVI Congresso Brasileiro de Meteorologia, Belém, p.1-5, 2010.

TEODORO, P. E.; OLIVEIRA-JÚNIOR, J. F.; CUNHA, E. R.; CORREA, C. C. G.; TORRES, F. E.; BACANI, V. M.; GOIS, G.; RIBEIRO, L. P. Cluster analysis applied to the spatial and temporal variability of monthly rainfall in Mato Grosso do Sul State, Brazil. Meteorology and Atmospheric Physics (Print), Berlin, v.128, n.2, p.197-209, 2015.

WORLD METEOROLOGICAL ORGANIZATION - WMO. Wind measurements: Potential wind speed derived from wind speed fluctuations measurements, and the representativity of wind stations (J.P. van der Meulen). In: Proceedings of the WMO Technical Conference on Meteorological and Environmental Instruments and Methods of Observation (TECO-2000); 2000; Geneva. Geneva; 2000. Instruments and Observing Methods Report no.74, WMO/TD-n. 1028, p. 72.

YAMARTINO, R.J. A comparison of several single pass estimators of the standard deviation of wind direction. Journal Climate Applied Meteorology, Boston, v.23, n.9, p.1362-1366, 1984.

ZERI, M.; OLIVEIRA JÚNIOR, J.F., LYRA, G. B. Spatiotemporal analysis of particulate matter, sulfur dioxide and carbon monoxide concentrations over the city of Rio de Janeiro, Brazil. Meteorology and Atmospheric Physics (Print), Berlin, v.113, n.1, p.139-152, 2011. 